\title{
Simulation model for different bolted pre- combustion chamber (PCC) for spark ignition engine
}

\author{
Khairil Amri Muhamad Tajuddin ${ }^{1}$, Musthafah Mohd Tahir ${ }^{1,2,{ }^{*}, \text { Mohd Azli Salim }}{ }^{1,2}$, Muhd \\ Ridzuan Mansor ${ }^{1,2}$, Mohd Zaid Akop ${ }^{1,2}$ and Adzni Md. Saad ${ }^{1,2}$ \\ ${ }^{1}$ Faculty of Mechanical Engineering, Universiti Teknikal Malaysia Melaka, Hang Tuah Jaya, 76100, \\ Durian Tunggal, Melaka, Malaysia. \\ ${ }^{2}$ Centre for Advanced Research on Energy, Universiti Teknikal Malaysia Melaka, Hang Tuah Jaya, \\ 76100, Durian Tunggal, Melaka, Malaysia.
}

\begin{abstract}
In an engine, two combustion chamber are present in the cylinder. First, the main combustion chamber and the other is called the auxiliary combustion chamber also known as pre-combustion chamber (PCC). The PCC size is small than the main combustion chamber size. In this research, four concept designs are developed for bolted PCC design. CATIA V5 R20 software is used for designing process. After that, Computational Fluid Dynamic (CFD) simulation is used to analyze each type of the bolted PCC powered with natural gas fuel by ANSYS Fluent 16.0 simulation software. Each of the bolted PCC simulation investigated by its flow behavior for the velocity vectors and turbulence kinetic energy (TKE). This PCC can give bigger effect to the engine performance by $10 \%-15 \%$ using natural gas as fuel source.
\end{abstract}

\section{Introduction}

Currently there are increasingly in number of internal combustion engines (ICE) that are converted from using liquid fuel such as gasoline or diesel to use alternative gas fuel. The alternative gas fuel such as Compressed Natural Gas (CNG). This is due to government demand for limited availability liquid fossil fuel, demand for improving fuel efficiency and the most important to reduce environmental pollution. CNG has emerged at most promising and better alternative fuels for engine uses. In worldwide, the use of natural gas in ICE has many advantages including their abundance, low price, and adaptability as engine fuels, higher octane number and less exhaust emission compared to liquid fossil fuels [1]. However, CNG suffer from the problems of very low energy density.

Nowadays, improvement of engine performance has become an important issues for automotive manufacturer's leaders. In order to increase engine performance, many studies are carried out on emission formation and also combustion process. Other than that, there are two common method use in research field. The method is the experimental study and

\footnotetext{
* Corresponding author: musthafah@utem.edu.my
} 
mathematical simulations (thermo dynamical modelling, computational fluid dynamics (CFD) modelling, etc.) [2]. CFD is defined as the science of predicting fluid flow, heat transfer, mass transfer, chemical reactions, and related phenomena by solving the mathematical equations which govern these processes by means of computer based simulations [8]. It is easy to predict and analyze various details that are technically difficult such as cylinder process of gasoline combustion, temperature and pressure contours. The cylinder speed, the cylinder chamber geometry, fuel utilization, in-cylinder liquid dynamics and ignition devices utilized, speak to distinctive variables that influence the internal combustion [6]. For the most part, the principal air movements were filled into categories such as the rotary movement induced tangentially in the cylinder (swirl) and the rotary movement in the axial plane (tumble) [7].

Pre-combustion engine is an internal combustion engine in which carburetion is enhanced by method for a pre-combustion chamber. The fuel, or working blend, is initially sustained into the pre-combustion chamber for partially burned. At the point when the fuel mixture are ignited, the pressure in combustion chamber increases, as the result of heated fuel mixture and combustion products enters the combustion chamber over the piston cylinder. The steady rate of fuel combustion as it is removed from the pre-combustion chamber into the combustion chamber provide a uniform increment of pressure in cylinder for smoother operation of pre-combustion engine. For fuel pre-combustion chamber, the fuel utilization is about 6 to 8 percent lower by weight, and there are less toxic exhausts. In any case, stability and reliability of performance are diminished under few methods of operation. The pre-combustion chamber volume is generally from 25 to 30 percent of the main combustion chamber volume. Pre-combustion makes the turbulence required for the fuel and air to be properly mixed. Because of the differences in pre-combustion chamber designs, the way in which pre-combustion helps in making turbulence varies from one type of auxiliary combustion chamber to another. The disadvantages of pre-combustion chamber when the velocity of air and fuel mixture is too high during the entry from pre-chamber, so the heat loss is very high. This causes decrease in the thermal efficiency which can be counterbalanced by increasing the compression ratio. Cold starting will be troublesome as the air loses heat to chamber walls during compression process [9].

\section{Simulation setup}

\subsection{Design geometry of pre-combustion chamber (PCC)}

To begin the analysis, a solid geometry drawing of Pre-Combustion Chambers (PCC) must be created. A four geometry Pre-Combustion Chamber (PCC) has been designed by using CATIA V5R20.

\subsection{Computational fluid dynamic (CFD) by ANSYS workbench (FLUENT)}

Next, by using a Computational Fluid Dynamics (CFD), the fluent flow in these PreCombustion Chamber is calculated in order to choose which Pre-Combustion Chamber show higher performance. For this analysis, ANSYS Workbench is used. Simulation analysis consists of three elements which are pre-processing, solver and post-processing. Analysis on this simulation is at the volume inside a Pre-Combustion Chamber. 




Fig. 1. Elements in CFD simulation.

\subsection{Geometry creation / modification}

The simulation was done at the volume inside the Pre-Combustion Chamber (PCC). The PCC geometry was imported into ANSYS. The modification is done by converting the caps inside the PCC into solid part body. Figure shows the PCC designs imported into ANSYS.

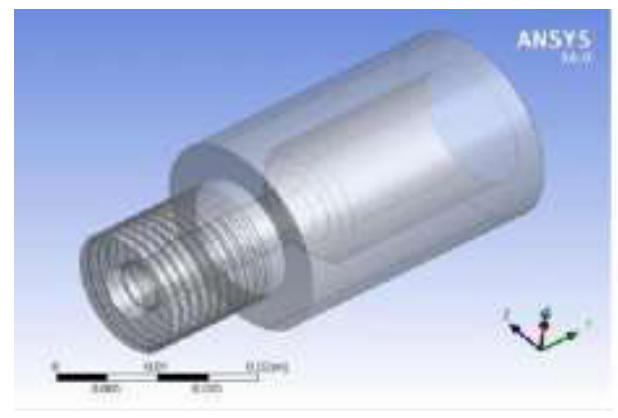

(a)

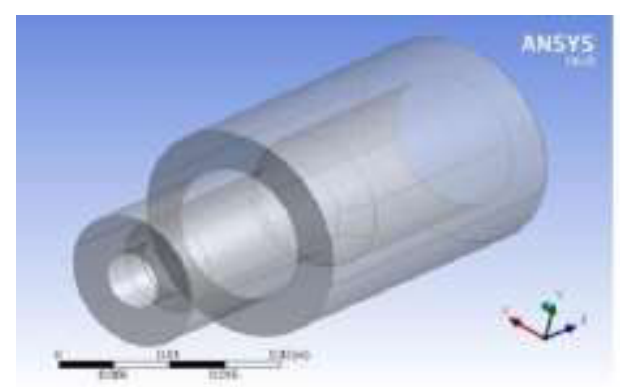

(c)

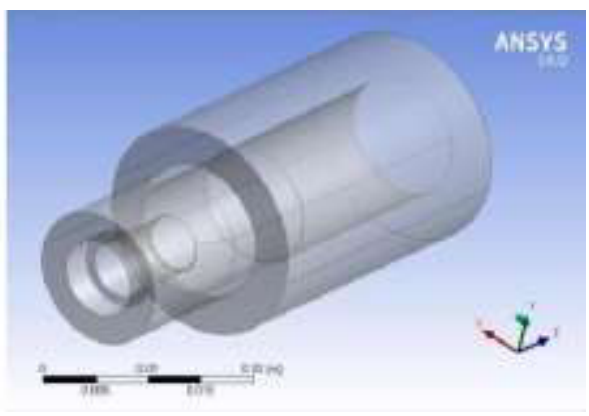

(b)

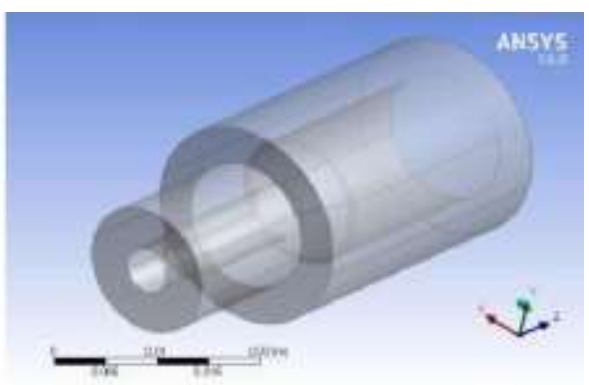

(d)

Fig. 2. Pre-combustion Chamber (PCC) geometry design.(a) Type 1 PCC design (b) Type 2 PCC design. (c) Type 3 PCC design. (d) Type 4 PCC design.

\subsection{Meshing}

Domain is required to be divided into discrete cells for a flow to be solved in order to determine the result's accuracy with the quality of the mesh. Boundary conditions is applied where the cells are grouped into boundary zones which are:

1. Inlet

2. Outlet

3. Wall solid 
4. Interior solid

Mixture of air and fuel is stimulating in this project and the velocity of each inlet is to be determined. Stated that air-fuel mixture in Pre-Combustion Chamber (PCC) of any one of claims $7,8,9,10$, or 11 , further comprising generating a flow filed velocity within about 1.0 meter per second and about 100.0 meter per second.

By using ANSYS-Mesh, the mesh was generated. From the mesh, the nodes, number of element and orthogonal quality of each PCC designs can be determined. Mesh quality are important before the analysis is run because they will affect the accuracy of the solution and the convergence time. The poor quality of meshing is defined when the orthogonal quality closer to 0 while the best quality of meshing is defined when the orthogonal quality closer to 1 . Table below show the nodes, number of element and orthogonal quality of each PCC designs. Figure below show the mesh quality of the simulation geometry for each PCC.

Table 1. The nodes, number of element and orthogonal quality of each PCC designs.

\begin{tabular}{||l|c|c|c|c|c|}
\hline Pre-Combustion & Nodes & Number of & & Orthogonal Quality & \\
\hline Chamber (PCC) & & Element & Minimum & Maximum & Average \\
\hline Type 1 Design & 12179 & 60952 & 0.30418 & 0.99394 & 0.85552 \\
\hline Type 2 Design & 57247 & 305068 & 0.17495 & 0.99579 & 0.85868 \\
\hline Type 3 Design & 2933 & 13328 & 0.30699 & 0.99858 & 0.85525 \\
\hline Type 4 Design & 15087 & 75874 & 0.25746 & 0.99978 & 0.8557 \\
\hline
\end{tabular}

\subsection{Solver setting}

Pressure based solver was used in this simulation which Energy model was defined. The time independent and the simulation in the solver is performed in steady state. K-epsilon model with near wall treatment of standard wall function was used as turbulent viscous model.

Next, the solution method parameter such as SIMPLE algorithm for Pressure-Velocity Coupling, Least Squares Cell Based for Gradient, Second Order for Pressure, Second Order Upwind for Momentum, First Order Upwind for Turbulent Kinetic Energy, First Order Upwind for Turbulent Dissipation Rate were used for all parameters.

\section{Results and discussion}

\subsection{Fluid flow (FLUENT)}

Pre-combustion chamber, and more particularly to the engine is designed to enhance fuel consumption and decontamination of exhaust gases. Whereby a stratification of the mixture gas and two stage combustion are performed. For this situation, the production of NOx of negative parts contained in exhaust gases may be suppressed. In any case, due of combustion of the rich mixture in the pre-combustion chamber, an unfavorable measure of hydrocarbons and carbon monoxide is produced [5]. In this situation, it is important that air should be supplied through the communicating passage into the pre-combustion chamber from the main combustion chamber without being adversely influenced by the throttling action because to the communicating passage and that the flame should be consistently diffused all through the main combustion chamber to effect the secondary or resulting combustion in that. In addition, the velocity of swirl flow of the mixture charge inside the pre-combustion chamber should be damped to this way lower the pressure increasing rate for the removal of the negative parts contained in exhaust gases and in addition the reduction in the level of noise incident to the combustion [5]. 


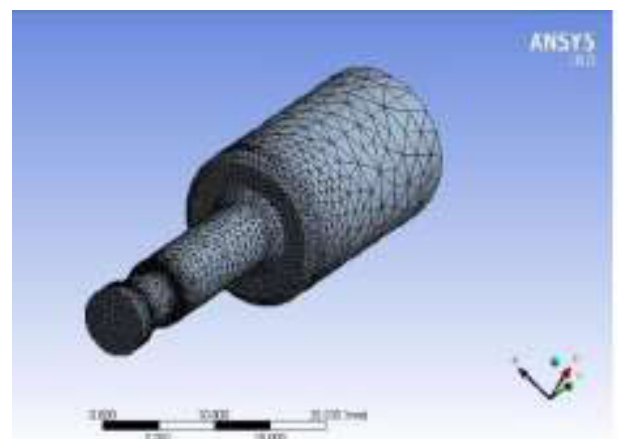

(a)



(c)

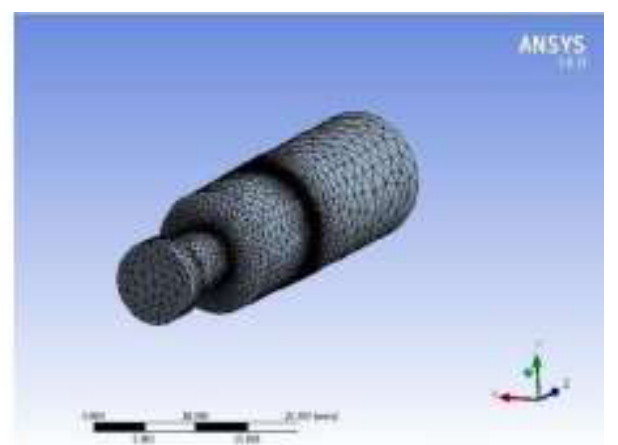

(b)

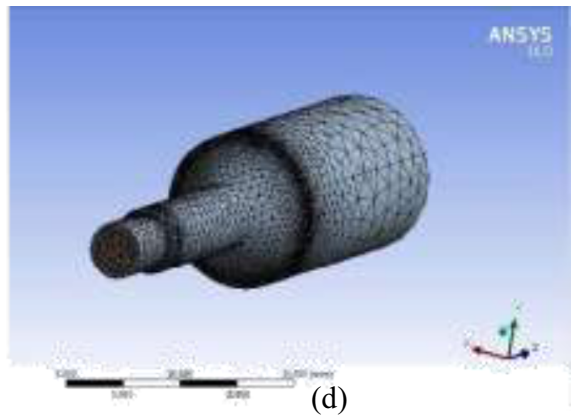

Fig. 3. Pre-combustion Chamber (PCC) meshing design. (a) Type1 PCC meshing. (b) Type 2 PCC meshing. (c) Type 3 PCC meshing. (d) Type 4 PCC meshing.

Likewise, the passage being considerably tangentially arranged relative to the inner surface of the pre-combustion chamber and being inclined relative to the axis of said cylinder whereby the swirl flows produced in the pre-combustion chamber interfere with each other as a result of their spaced centers to decrease the velocity of the swirl flows so that flame propagation of a fuel mixture charge is lowered and the amount of NOx in exhaust gas is decreased.

\subsection{Velocity vectors}

Results were analyzed and the simulation of the results were presented in graphical views. The velocity vector of the flow at the planes of each Pre-Combustion Chamber (PCC) designs were analyzed to determine the swirl and tumble pattern. To achieve the objectives of this project, the best of three of the PCC designs have been chose by comparing their velocity flow and the swirl pattern. Figure (a), (b), (c) and (d) show the plane where the results will be illustrated. From the figure below, determine the highest maximum velocity each of the PCC using ANSYS simulation result.

The velocity vector displayed on z-y axis plane indicates swirl flow in the each PCC. The vectors represent the velocity magnitudes. From figure above, it can be seen that the mixtures flows to the center of the PCC and the swirl is visible at the corner in each PCC designs. Fig. 6 shows the highest velocity flow followed by the velocity flow in Fig. 7, Fig. 4 and Fig. 5. This is due to long inlet passage inside it. The swirl pattern for Type 3 design of PCC in Fig. 6 shows the best flow among the others design where the second best is Type 4 design of PCC in Fig. 7 and followed by Type 2 design of PCC in Fig. 5 and Type 1 design of PCC in Fig. 4. From this comparison, it can concluded that the Type 2, Type 3 and Type 4 design of PCC are selected based on their best velocity and swirl pattern compared to the Type 1 designs. As the burning air and fuel and combustion products from the pre-combustion chamber involve a much bigger volume than the spark plug arc, the 
combustion process within the main combustion chamber is completed much more quickly, resulting in greater engine efficiency [3]. From the past study, a lean air/fuel ratio can increase the probability of irregularities in burning because there is a little margin of fuel in the combustion chamber in excess of that amount necessary for proper combustion process. Especially if the fuel is not mixed adequately, there can be regions of gas near the spark plug gap at the time of combustion that do not contain sufficient fuel for consistent burning. Accordingly, it is to give a combustion system including a main combustion chamber and a pre-combustion chamber which advances steady and consistent combustion, subsequently enhancing engine efficiency, reducing toxic exhaust emissions, and lessening fuel consumption [4].

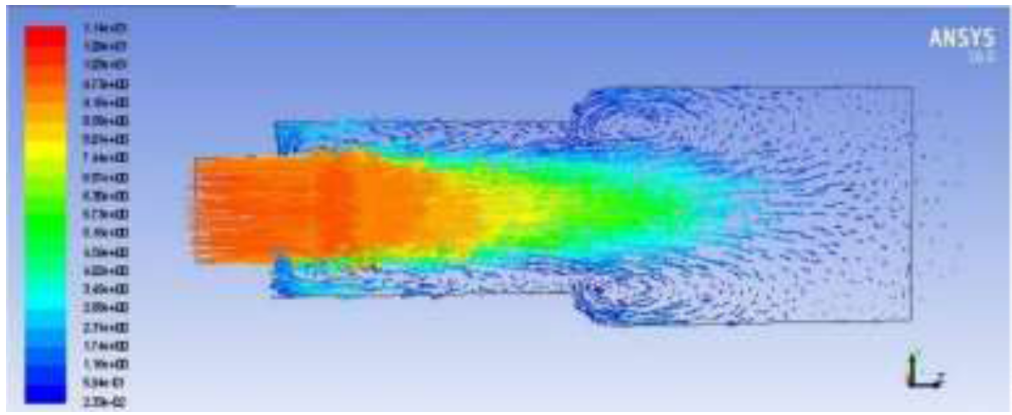

Fig. 4. Type $1 \mathrm{PCC}$ velocity vectors (Maximum velocity $=1.6 \mathrm{~m} / \mathrm{s}$ ).

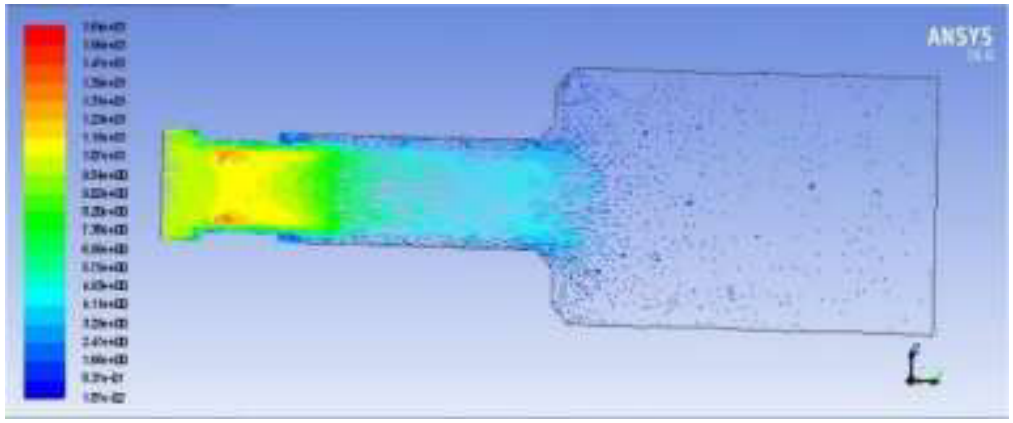

Fig. 5. Type 2 PCC velocity vectors (Maximum velocity $=2.5 \mathrm{~m} / \mathrm{s}$ ).

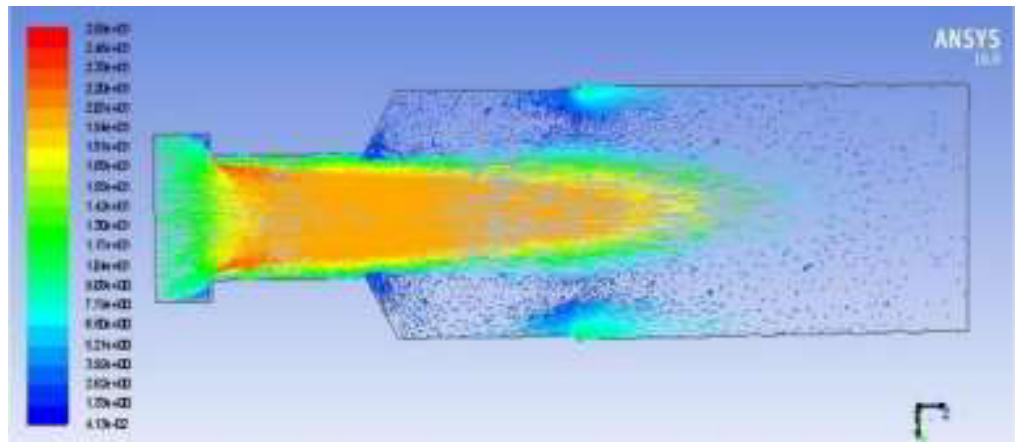

Fig. 6. Type 3 PCC velocity vectors (Maximum velocity $=1.14 \mathrm{~m} / \mathrm{s}$ ). 


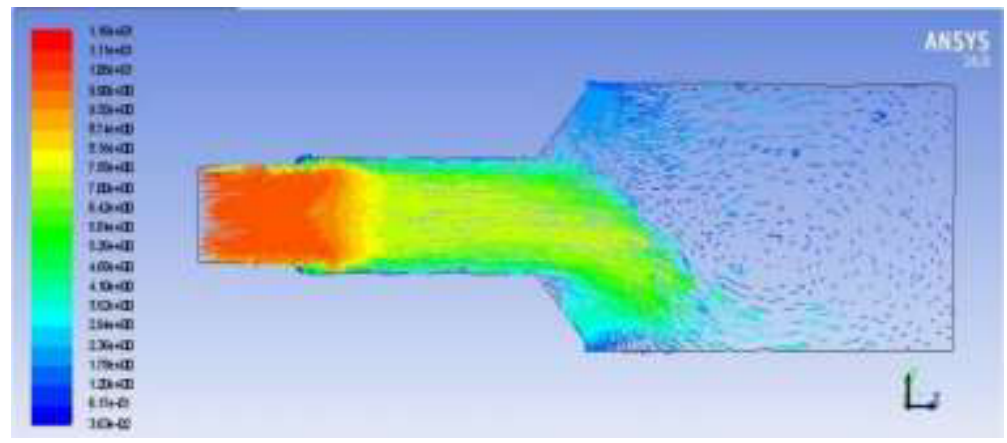

Fig. 7. Type 4 PCC velocity vectors (Maximum velocity $=1.16 \mathrm{~m} / \mathrm{s}$ ).

\subsection{Turbulence kinetic energy (TKE)}

The irregularity of flows is represented by turbulence and it is used to find the best air-fuel mixing preparation before combustion occurs and help to increase the combustion rates. By referring the Figure (e), (f), (g) and (h), the brightest color indicates higher value of Turbulence Kinetic Energy (TKE).

The brightest colors are more visible in Fig. 9, Fig. 10 and Fig. 11. From Fig. 9, the Turbulent Kinetic Energy show brightest at the center of Pre-Combustion Chamber (PCC). PCC in Fig. 10, its TKE show brightest at the inlet of the air-fuel mixture. Compare to PCC in Fig. 11, the turbulent kinetic energy show brighter than PCC in Fig. 8, even though PCC in Fig. 11, its turbulent kinetic energy are not at the best compare to PCC in Fig. 9 and Fig. 11. From this comparison, it can concluded that the Type 2 and Type 3 of PCC are selected based on their best turbulent kinetic energy compared to another designs.

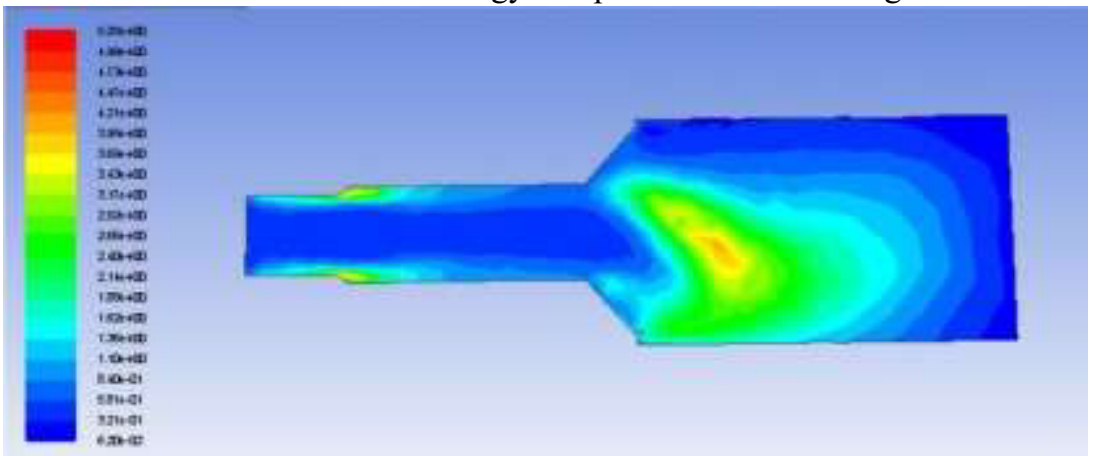

Fig. 8. Contours of Turbulence Kinetic Energy (TKE) for Type 1 PCC $\left({ }^{2} /{ }^{2}\right)$.

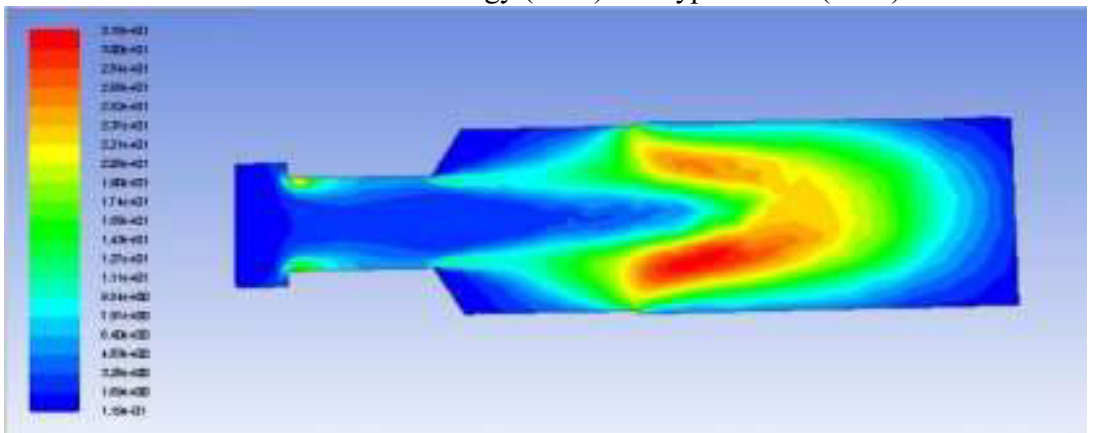

Fig. 9. Contours of Turbulence Kinetic Energy (TKE) for Type 2 PCC $\left({ }^{2} / 2\right)$. 


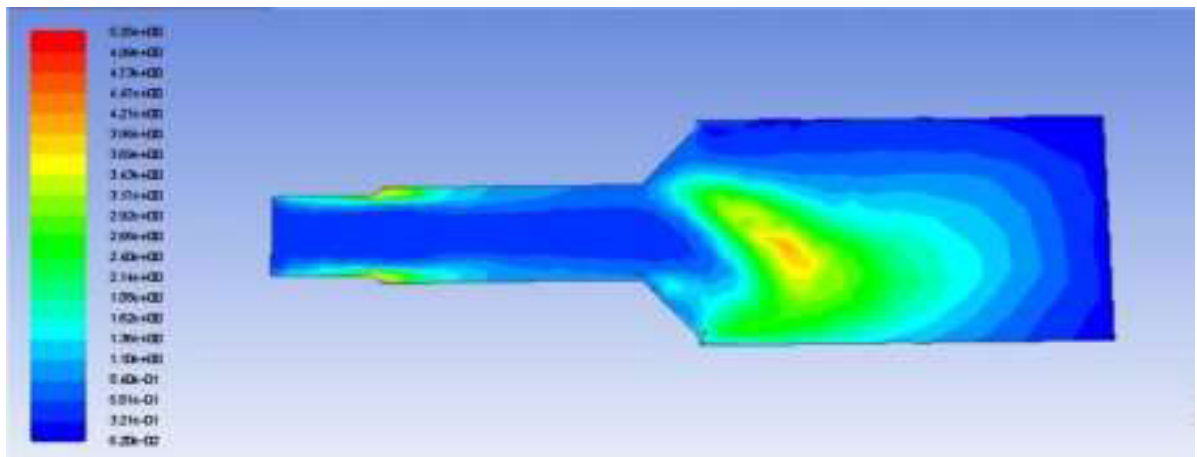

Fig. 10. Contours of Turbulence Kinetic Energy (TKE) for Type 3 PCC $\left({ }^{2} / 2\right)$.

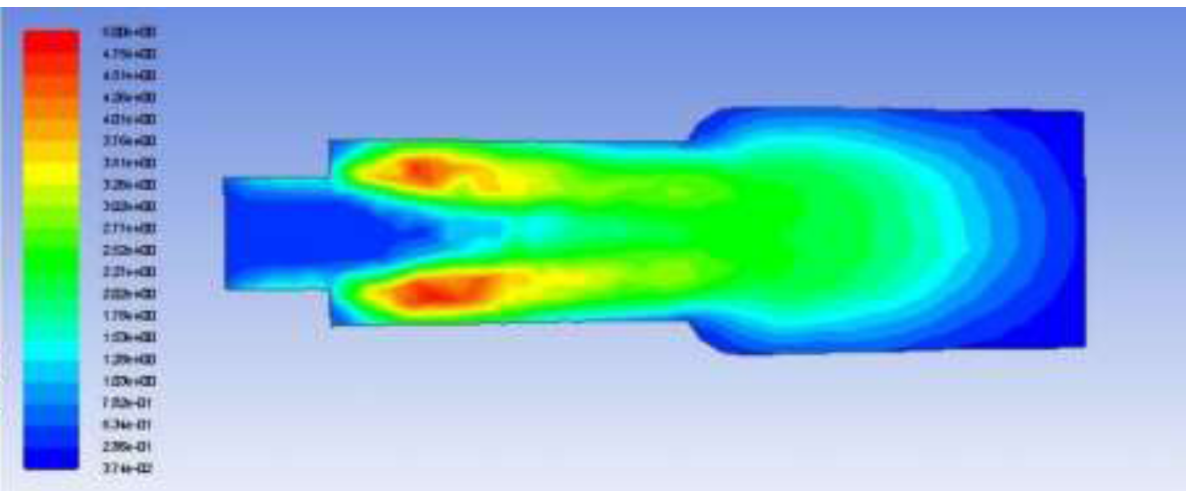

Fig. 11. Contours of Turbulence Kinetic Energy (TKE) for Type 4 PCC $(2 / 2)$.

\section{Conclusions}

In this paper, the mixture formation, combustion process and flow field were simulated using computational fluid dynamic (CFD) by ANSYS simulation software. As for interpretation of the results:

1. Swirl is more visible in Fig. 6 in fluid fluent shows the highest velocity flow. When the burning fuel and air occupy much larger volume, the combustion process in PCC has completed much more rapidly, resulting in greater engine efficiency.

2. For the Turbulence Kinetic Energy (TKE), Fig. 9 shows the brightest colour at the centre of the PCC. Meanwhile, the Fig. 10 shows the brightest colour at the inlet of the PCC for the air-fuel mixture. Therefore, it can help to increase the combustion process rates.

The authors would like to acknowledge GTeV research group, CARE, UTeM for providing the technical support and facilities to perform this study. The author would like to also acknowledge UTeM and FKM under research grant PJP/2014/FKM(6A)/SA1323.

\section{References}

1. R.G. Papagiannakis C.D. Rakopoulos D.T. Hountalas D.C. Rakopoulos, "Emission characteristics of high speed, dual fuel, compression ignition engine operating in a wide range of natural gas/diesel fuel proportions", Fuel 89 (2010) 1397-1406.

2. R. Barzegar, S. Shafee, S. Khalilarya, : Computational Fluid Dynamic Simulation of 
the Combustion Process, Emission Formation and the Flow Field in an In-Direct Injection Diesel Engine, THERMAL SCIENCE: 2013, Vol. 17, No. 1, pp. 11-23.

3. D. F. Paul, "Swirl flow precombustion chamber," U.S. Patent 5555867, Sep. 17, (1996)

4. L. K. George, "Pre-combustion chamber spark plug and method of igniting lean fuel," U.S. Patent 4864989, Sept. 12, (1988)

5. T. Suzuki, "Internal combustion engine provided with precombustion chamber," U.S. Patent 4066045, Jan. 3, (1978)

6. Z. Barbouchi, and J. Bessrour, "Turbulence study in the internal combustion engine," Journal of Engineering and Technology Research, Vol. 1 (9), pp. 194-202, (2009)

7. J.B. Heywood, "Fluid motion within the cylinder of internal combustion engines," ASME, J. Fluids Eng., 109, pp. 3-35, (1987)

8. H.K. Versteeg, W. M., (1995). An introduction to computational fluid dynamics: The finite volume method. England: Longman Scientific \& Technical 